\title{
Rekonfigurasi Jaringan Distribusi Listrik Universitas Andalas Untuk Memperbaiki Indeks Energy Not Supplied
}

\author{
Shaumi Novila Asri, Adrianti* dan Muhammad Nasir \\ Jurusan Teknik Elektro, Fakultas Teknik, Universitas Andalas \\ *Corresponding author, e-mail: adrianti@eng.unand.ac.id
}

\begin{abstract}
Abstrak - Penelitian ini bertujuan untuk memperbaiki keandalan jaringan distribusi listrik Universitas Andalas dengan rekonfigurasi jaringan. Perhitungan keandalan dilakukan menggunakan metode blok diagram seri-paralel. Parameter keandalan yang dihitung yaitu laju kegagalan, annual downtimes serta Energy Not Supplied (ENS). Rekonfigurasi dilakukan dengan fokus pada titik-titik beban yang memiliki indeks ENS yang terbesar. Titik-titik beban tersebut direkonfigurasi dengan memindahkan supply dayanya ke gardu yang lebih dekat dengan penambahan saluran baru. Akibatnya bentuk jaringan berubah menjadi konfigurasi loop, tetapi pada saat beroperasi jaringan tetap dalam konfigurasi radial. Dari rekonfigurasi yang diusulkan, nilai ENS sistem distribusi Universitas Andalas berhasil diturunkan dari nilai tertinggi 315,191 kWjam/tahun menjadi 142,864 kWjam/tahun. Sehingga lama dan frekuensi pemadaman listrik di titik-titik beban berhasil dikurangi yang pada akhirnya diharapkan dapat membantu meningkatkan produktivitas di Universitas Andalas
\end{abstract}

Kata Kunci : Energy not supplied, keandalan, rekonfigurasi, jaringan distribusi

\begin{abstract}
This research aims to improve the reliability of electrical distribution networks of Universitas Andalas using network reconfiguration. Reliability calculation is carried out using series-parallel block diagram. The calculated reliability indexes are failure rates, annual down times and energy not supplied (ENS). The reconfiguration is focused for load points that have highest ENS. For these load points, reconfiguration was done by transferred their power supply to nearer distribution substation by installed new feeders. As a result, the distribution network changes it shape into loop configuration, although during operation it still has radial configuration. The reconfiguration has been success in reducing the ENS values of Universitas Andalas distribution network. The highest load point's ENS i.e. 315,191 $\mathrm{kWh} /$ year has been reduced into $142,864 \mathrm{kWh} /$ year. Therefore, frequency and duration of electricity outage at load points have been reduced and its implication can increase the productivity in Universitas Andalas.
\end{abstract}

\section{Keywords : Energy not supplied, reliability, reconfiguration, distribution network}

\section{Pendahuluan}

Jaringan distribusi listrik Universitas Andalas (Unand) disuplai dari feeder $20 \mathrm{kV}$ PLN melalui 3 gardu hubung yaitu gardu Keperawatan, gardu Teknik dan gardu Kedokteran. Saat ini sebagian besar beban terhubung ke gardu Keperawatan. Akibatnya beberapa titik beban berada cukup jauh dari gardu keperawatan sehingga tingkat keandalannya rendah.

Disamping itu konfigurasi radial yang digunakan pada jaringan distribusi Unand menyebabkan tidak mungkin dilakukan manuver jaringan saat salah satu titik di jaringan mengalami gangguan. Akibatnya waktu pemadaman akan sangat tergantung pada lamanya perbaikan yang dilakukan.

Penelitian ini bertujuan untuk memperoleh konfigurasi baru jaringan listrik Unand yang memiliki indeks keandalan yang lebih baik. Indeks keandalan yang digunakan adalah frekuensi pemadaman/laju kegagalan (failure rate), waktu perbaikan (repair time), lama pemadaman, tahunan (annual down time) dan besar energi yang tidak tersalurkan (ENS, Energy Not Supplied).

Ada berbagai indeks keandalan system distribusi tenaga listrik yang umum digunakan seperti indeks berorientasi pelanggan (SAIDI, SAIFI, CAIDI, ASAI, ASUI), indeks yang berorientasi energi (ENS) serta frekuensi dan durasi [1-3]. Frekuensi dan durasi serta ENS dipilih sebagai indeks yang digunakan pada penelitian ini karena lebih cocok untuk distribusi listrik di Unand dibandingkan indeks yang berorientasi pelanggan. Hal ini karena jika dilihat 
dari jumlah pelanggan, maka jaringan Unand hanya dibayai oleh satu pelanggan yaitu Universitas Andalas.

Terdapat berbagai metoda perhitungan yang telah digunakan untuk analisa keandalan sistem distribusi $[1,2,4]$. Namun yang paling sederhana adalah metoda diagram blok. Dengan metoda diagram blok dapat dihitung failure rate dan repair time sistem secara langsung. Hal ini tidak dapat diperoleh jika menggunakan metoda seperti Fault tree analysis dan Bayesian network [5, 6]. Metoda diagram blok juga tidak membutuhkan banyak data dan proses perhitungan jika dibandingkan dengan metoda seperti Markov process [7] dan Monte Carlo [8]. Sehingga pada penelitian ini dipilih metoda diagram blok untuk perhitungan indeks keandalan.

Rekonfigurasi diharapkan menghasilkan jaringan yang tidak lagi radial sehingga saat terjadi gangguan dapat dilakukan manuver saluran pada titik-titik beban yang mengalami pemadaman sehingga akan mendapat suplai melalui jalur lain.

\section{Keandalan Jaringan Distribusi}

Analisis keandalan jaringan distribusi biasanya cukup sederhana sehingga bisa dianalisa menggunakan diagram blok keandalan (reliability block diagram). Langkah-langkah analisa keandalan dengan diagram blok keandalan yaitu : menetapkan kriteria kegagalan, memodelkan diagram blok keandalan, menganalisis modus kegagalan dan perhitungan keandalan sistem [9].

Kriteria kegagalan yang digunakan adalah beban gagal mendapat pasokan daya listrik dari jaringan distribusi. Semakin lama durasi terputusnya pasokan listrik ini semakin rendah keandalannya. Semakin besar daya rata-rata sebuah titik beban, semakin besar pula jumlah energi yang tidak dapat disalurkan untuk suatu satuan waktu.

Jaringan distribusi dari gardu hubung hingga titik beban dimodelkan dengan diagram blok yang komponen-komponennya terhubung seri atau parallel atau gabungan keduanya tergantung konfigurasi jaringan. Pada jaringan yang murni radial, komponen-komponen jaringan akan terhubung secara seri. Sedangkan pada jaringan loop, diagramnya akan merupakan gabungan seri dan paralel.

Definisi komponen terhubung seri secara keandalan adalah jika salah satu komponen mengalami kegagalan, maka sistem akan otomatis gagal. Untuk komponen yang terhubung parallel, kegagalan salah satu komponen tidak akan mengakibatkan sistem menjadi gagal. Sistem baru akan gagal jika semua komponen yang terhubung parallel mengalami kegagalan. Contoh sederhana dua komponen terhubung seri diberikan oleh Gambar 1. Failure rate sistem ini diberikan oleh persamaan (1).

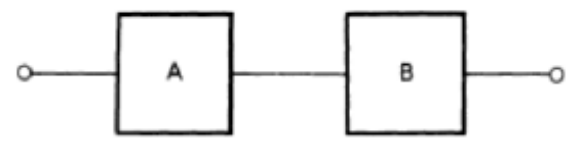

Gambar 1. Konfigurasi seri

$$
\lambda_{s}=\lambda_{A}+\lambda_{B}
$$

Dimana $\lambda_{S}=$ failure rate sistem seri

$\lambda_{A}=$ failure rate komponen $\mathrm{A}$

$\lambda_{B}=$ failure rate komponen $\mathrm{B}$

Untuk n komponen terhubung seri, maka failure rate sistem $\left(\lambda_{s}\right)$ adalah

$$
\lambda_{s}=\sum_{i=1}^{n} \lambda_{i}
$$

dan repair time sistem $\left(r_{s}\right)$ adalah

$$
r_{S}=\frac{\sum_{i=1}^{n} \lambda_{i} r_{i}}{\lambda_{s}}
$$

Dimana

$\lambda_{i}=$ failure rate komponen $\mathrm{i}$

$r_{i}=$ repair time komponen $\mathrm{i}$

Annual down time dari sistem $\left(U_{S}\right)$ dapat dihitung dengan

$$
U_{s}=\lambda_{s} r_{s}
$$

Untuk jaringan distribusi yang terhubung loop, dalam kondisi normal tetap bekerja secara radial, namun jika terjadi gangguan akan mempunyai jalur cadangan yang bisa dimanuver untuk mempertahankan pasokan daya ke titik beban. Konfigurasi ini disebut juga konfigurasi standby (Gambar 2). Perhitungan failure rate dan repair time sistem stand by diberikan oleh persamaan (5) dan persamaan (6) [10].

$$
M T T F=\sum_{i=1}^{n} \frac{1}{\lambda_{i}}
$$

Dimana

MTTF $=$ mean time to failure 


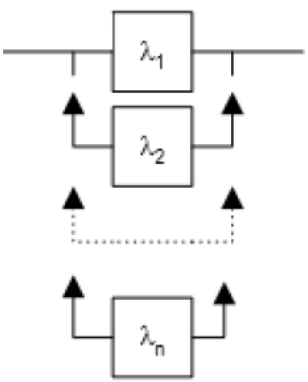

Gambar 2. Konfigurasi standby

$$
r_{S}=\frac{1}{\sum_{i=1}^{n} \frac{1}{r_{i}}}
$$

Energy Not Supplied (ENS) adalah indeks yang digunakan dalam perhitungan keandalan. ENS adalah jumlah total energi listrik yang tidak tersalurkan oleh system dalam satu tahun. Persamaan matematisnya dapat ditulis:

$$
E N S=L_{a(i)} \cdot U_{i}
$$

Dimana

$L_{a(i)}=$ beban rata-rata di titik beban $\mathrm{i}$

$U_{i}=$ annual down time, yaitu total waktu dalam setahun titik beban i tidak mendapat suplai daya.

Kegagalan titik beban untuk mendapat suplai daya disebabkan oleh berbagai moda kegagalan/kerusakan yang mungkin dialami oleh setiap komponen penyusun jaringan distribusi. Data failure rate dan repair time untuk setiap moda kegagalan komponen-komponen jaringan diambil dari data statistik tempat lokasi studi. Jika data tersebut tidak tersedia, dapat digunakan data statistik dari komponen yang serupa dari tempat lain. Misalnya data statistik yang dikumpulkan oleh IEEE [11].

Berdasarkan diagram blok dan data komponen dapat dihitung indeks keandalan untuk setiap titik beban. Secara teoritis beban yang berada lebih jauh dari gardu hubung akan memiliki indeks keandalan lebih rendah dari pada beban yang dekat dengan gardu hubung. Hal ini disebabkan jumlah komponen yang menyusun diagram blok titik beban lebih banyak sehingga kemungkinan gangguannya akan lebih tinggi.

\section{Metoda}

Penelitian diawali dengan perhitungan keandalan titik-titik beban tegangan menengah di jaringan distribusi listrik Unand. Dari perhitungan indeks keandalan ENS akan diperoleh titik-titik beban yang memiliki keandalan rendah (ENS tinggi). Titik-titik tersebut menjadi kandidat yang perlu diperbaiki tingkat keandalannya dengan rekonfigurasi jaringan.

Untuk perhitungan keandalan, setiap komponen jaringan distribusi dimasukkan dalam pemodelan blok diagram. Karena tidak ada data statistik gangguan dari komponen jaringan distribusi unand yang dapat digunakan, pada penelitian ini digunakan data failure rate dan repair time dari data IEEE [11]

Single line diagram jaringan distribusi Unand ditunjukkan oleh Gambar 3. Suplai daya dari PLN diterima melalui gardu Kedokteran (gardu dokter), gardu Teknik (gardu teknik) dan gardu Keperawatan (gardu rawat). Gardu hubung Rumah Sakit Unand tidak diikutsertakan dalam penelitian ini karena berdasarkan analisa, efek posisinya yang cukup jauh dari titik beban lain, tidak dapat membantu perbaikan keandalan.

Karena di kampus Unand terdapat 3 gardu hubung, maka dimungkinkan untuk memindahkan suplai titik-titik beban ke gardu hubung lain untuk memperbaiki keandalan. Titik-titik beban dengan keandalan rendah akan dihubungkan dengan gardu hubung lain yang cukup dekat sehingga memiliki dua suplai daya yang salah satunya merupakan cadangan (terhubung dengan saklar normally open). Jalur dengan tingkat keandalan yang lebih tinggi dipilih sebagai jalur untuk kondisi normal, sedangkan yang berkeandalan lebih rendah sebagai cadangan. Sehingga diperoleh titik beban yang dalam kondisi operasi tetap berkonfigurasi radial, namun jika terjadi gangguan dapat dipindahkan ke jalur lain sehingga pasokan daya tetap dapat diterima. Akibat rekonfigurasi ini, kapasitas trafo dan saluran perlu kajian ulang karena kapasitasnya mungkin tidak sesuai lagi.

\section{Hasil dan Pembahasan}

Berdasarkan hasil perhitungan keandalan titiktitik beban, diperoleh nilai ENS sebelum rekonfigurasi seperti ditunjukkan pada Tabel 1. Dari Tabel 1 dapat dilihat bahwa titik-titik beban yang rendah tingkat keandalannya adalah MIPA, Pertanian, Peternakan serta PKM. Keempat titik beban ini mendapat suplai dari gardu Fakultas Keperawatan dan berada pada bagian ujung jaringan. 

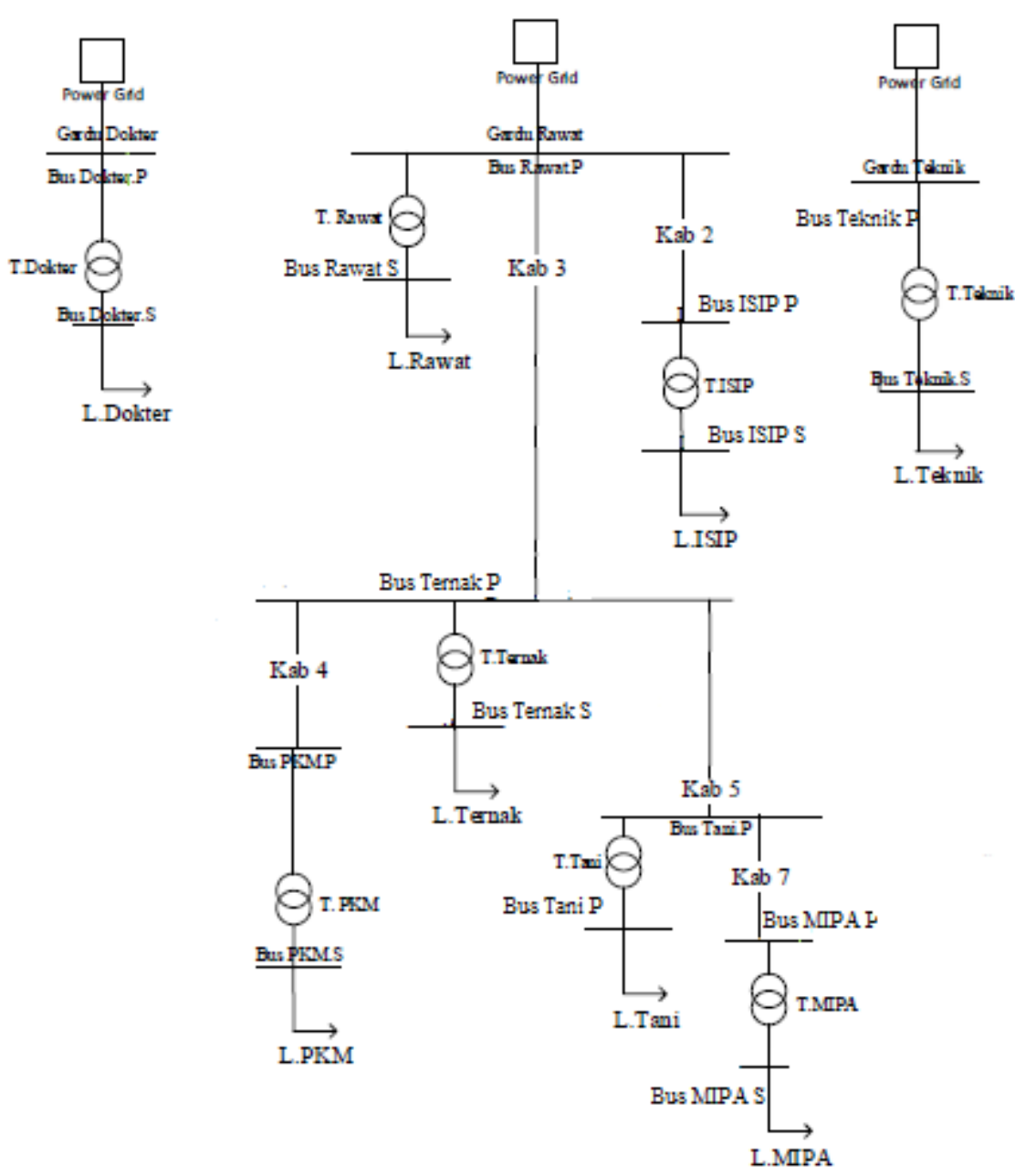

Gambar 3. Single line diagram jaringan distribusi Unand sebelum rekonfigurasi

Tabel 1. Hasil perhitungan nilai keandalan titik-titik beban sebelum rekonfigurasi

\begin{tabular}{|lclllr|}
\hline Titik beban & $\begin{array}{l}\text { Beban } \\
(\mathrm{KW})\end{array}$ & $\lambda$ (gangguan/tahun) & $\begin{array}{l}\mathrm{r} \\
\text { (jam/gangguan) }\end{array}$ & $\begin{array}{l}\mathrm{U} \\
\text { (jam/tahun) }\end{array}$ & $\begin{array}{l}\text { ENS } \\
\text { (kwh/tahun) }\end{array}$ \\
\hline Keperawatan & 118 & 0,01735 & 26,11668 & 0,45312 & 53,469 \\
ISIP & 156 & 0,02554 & 26,51071 & 0,67721 & 94,132 \\
Peternakan & 139 & 0,03235 & 22,01452 & 0,71222 & 111,106 \\
PKM & 268 & 0,04070 & 23,01815 & 0,93693 & 124,612 \\
Pertanian & 233 & 0,04094 & 22,92346 & 0,93838 & 218,643 \\
MIPA & 133 & 0,05177 & 22,71817 & 1,17609 & 315,191 \\
Teknik & 199 & 0,01735 & 26,11668 & 0,45312 & 90,172 \\
Kedokteran & 226 & 0,01735 & 26,11668 & 0,45312 & 102,406 \\
\hline
\end{tabular}

Untuk rekonfigurasi jaringan, keempat tititk beban ini akan dipindahkan suplainya ke gardu lain sehingga tidak lagi berada diujung jaringan. Beban MIPA dan pertanian serta perternakan dipindahkan ke gardu Teknik, sementara beban
PKM dihubungkan ke gardu Kedokteran untuk memperoleh back up.

Saluran lama yang menghubungkan bebanbeban ini ke gardu Keperawatan tetap dipertahankan namun ditambahkan saklar. 
Sehingga semua titik beban memiliki hubungan ke tiga gardu akibat adanya koneksi melalui bus PKM dan bus MIPA. Single line diangram setelah rekonfigurasi ditunjukkan pada gambar 4.

Akibat rekonfigurasi ini, komponen baru yang ditambahkan ke jaringan distribusi Unand yaitu :

a. Saluran 11 (Kab 11) yang menghubungkan sisi $20 \mathrm{KV}$ gardu teknik dengan gardu MIPA. Saklar normally open (SW1) ditempatkan pada saluran antara Peternakan dan Pertanian. Saklar normally closed (SW2) ditempatkan pada saluran antara MIPA dengan Teknik. Panjang saluran 11 ini adalah 926 meter.

b. Saluran 12 (Kab 12) menghubungkan antara gardu Kedokteran dengan PKM yang dilengkapi dengan saklar normally open (SW3). Saluran antara bus Peternakan dan bus Keperawatan dilengkapi dengan saklar normally closed (SW4). Panjang saluran 12 ini adalah 439 meter.

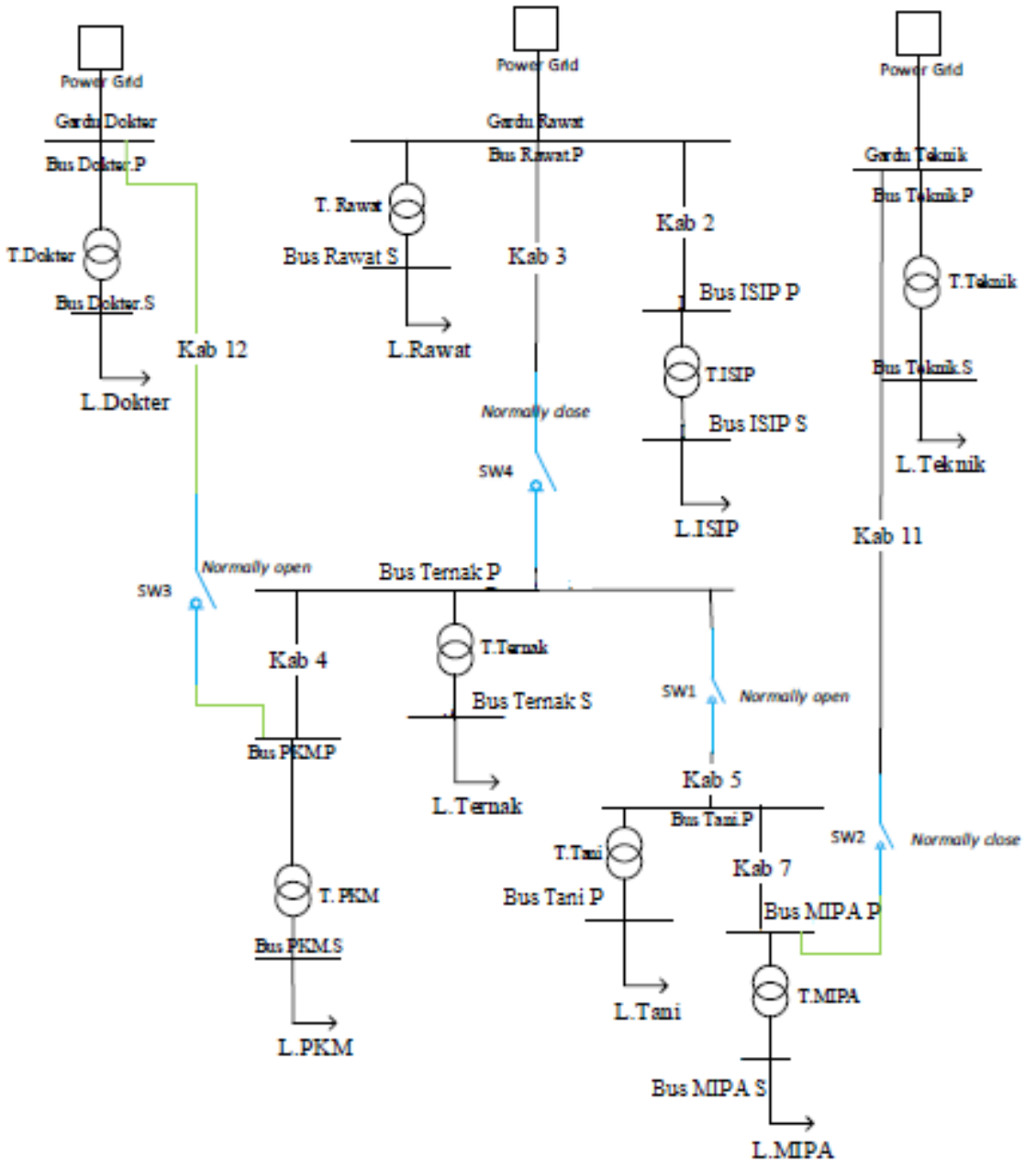

Gambar 4. Single line diagram jaringan distribusi Unand setelah rekonfigurasi

Rekonfigurasi ini juga mengharuskan Unand untuk menambah kontrak dayanya pada gardu Teknik dan Kedokteran. Besar daya yang dibutuhkan oleh kedua gardu ini tergantung pada kondisi jaringan/manuver jaringan yang dilakukan.

Berdasarkan berbagai skenario gangguan di jaringan yang mungkin terjadi, maka akan diperoleh berbagai kondisi. Setiap kondisi ini kemudian disimulasikan aliran dayanya dengan software ETAP untuk pengecek level tegangan dan dayanya. Kebutuhan daya maksimum pada tiap gardu hubung ditunjukkan pada tabel 2 . Terlihat kontrak daya di gardu teknik dan gardu kedokteran harus dinaikkan jika konfigurasi yang diusulkan akan direalisasikan. 
Tabel 2. Kapasitas Daya pada Gardu Hubung

\begin{tabular}{|l|cc|}
\hline \multirow{2}{*}{ Gardu } & \multicolumn{2}{|c|}{ Daya Gardu (kW) } \\
\cline { 2 - 3 } & $\begin{array}{l}\text { Sebelum } \\
\text { rekonfigurasi } \\
\text { (kontrak) }\end{array}$ & $\begin{array}{l}\text { Maksimum } \\
\text { Daya Setelah } \\
\text { rekonfigurasi }\end{array}$ \\
\hline Keperawatan & 1700 & 1330 \\
Teknik & 425 & 1330 \\
Kedokteran & 425 & 833 \\
\hline
\end{tabular}

Berdasarkan analisa aliran daya, diperoleh bahwa besar arus maksimum yang mungkin mengalir pada setiap saluran masih berada dalam batas kuat hantar arus saluran. Sehingga tidak ada kabel saluran yang perlu diganti. Selanjutnya, efek penambahan koneksi dari gardu Kedokteran ke beban PKM adalah dibutuhkannya pembangunan gardu di PKM untuk menggantikan gardu tiang yang ada sebelumnya guna memfasilitasi dua suplai daya yang dapat diterima titik beban PKM.

Nilai indeks keandalan titik-titik beban setelah rekonfigurasi dihitung menggunakan diagram blok. Perbandingan indeks keandalan titik-titik beban sebelum dan sesudah rekonfigurasi ditunjukkan pada grafik di Gambar 5 sampai 7.

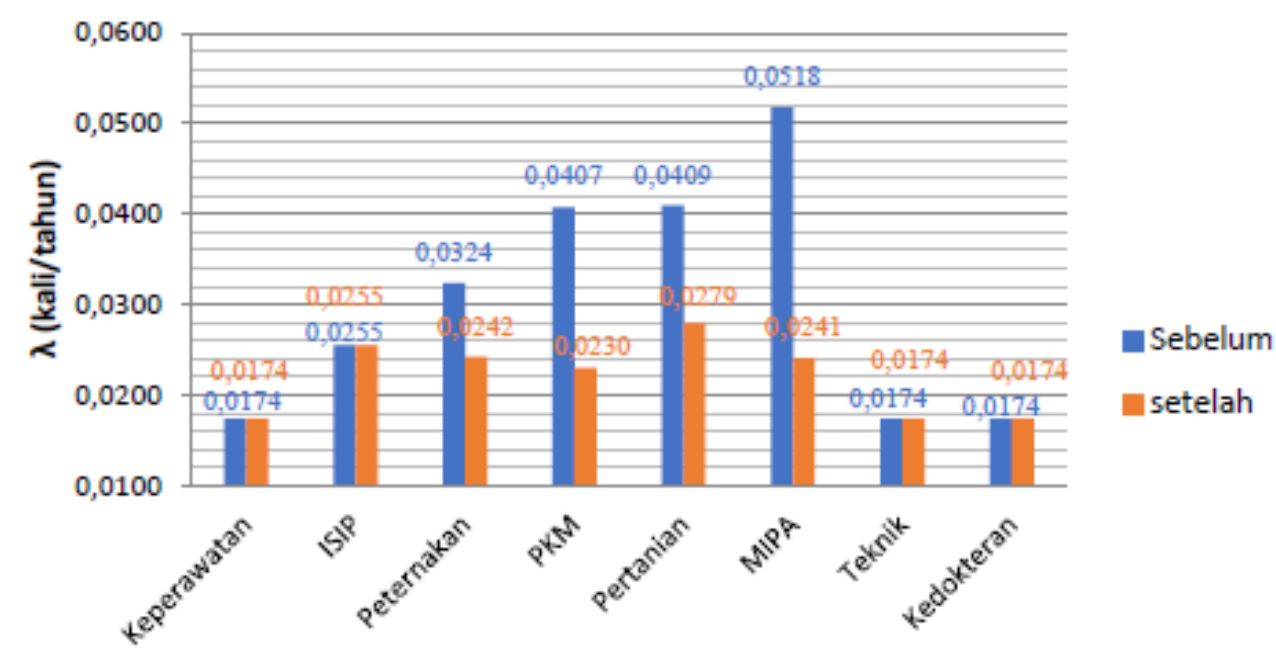

Nama Beban

Gambar 5. Perbandingan failure rate titik beban sebelum dan sesudah rekonfigurasi

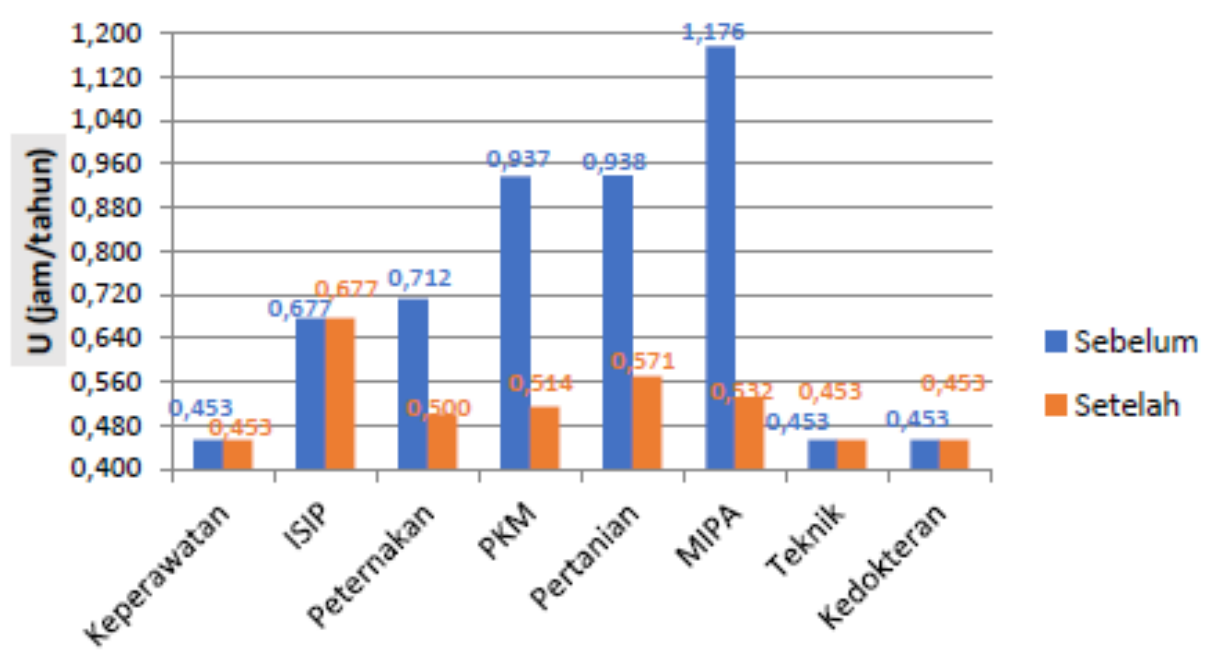

Nama beban (Fakultas)

Gambar 6. Perbandingan annual downtimes titik-titik beban sebelum dan sesudah rekonfigurasi 


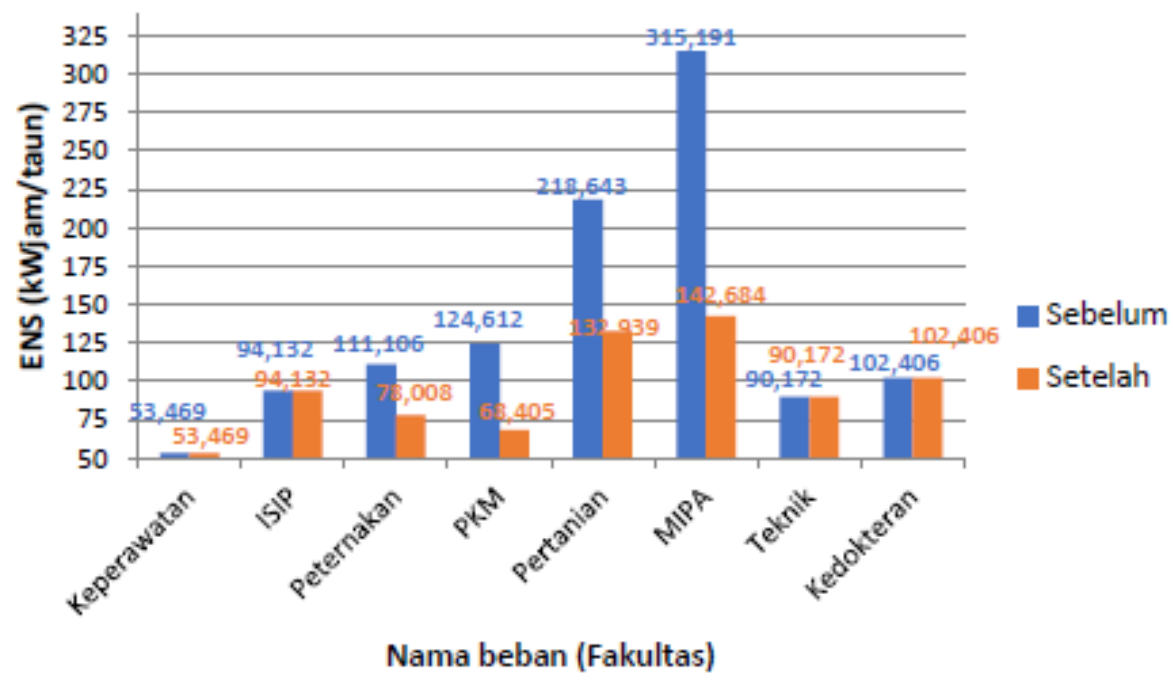

Gambar 7. Perbandingan ENS sebelum dan sesudah rekonfgurasi

Dari grafik pada Gambar 5 sampai 7 dapat dilihat bahwa indeks keandalan (failure rate, annual downtimes dan ENS) setelah rekonfigurasi sudah lebih baik dari pada sebelum rekonfigurasi. Pada Gambar 5, failure rate ke empat titik beban yang paling tidak andal (Peternakan, Pertanian MIPA dan PKM) sudah berhasil diturunkan secara sangat signifikan. Begitu juga dengan nilai annual downtimes di grafik Gambar 6. Pada Gambar 7, nilai ENS keempat titik beban juga turun sangat signifikan. ENS MIPA yang sebelum rekonfigurasi memiliki nilai terbesar yaitu $315,191 \mathrm{kWh} /$ tahun dapat diturunkan menjadi 142,684 kWh/tahun. Hal ini menunjukkan bahwa rekonfigurasi yang dilakukan sudah berhasil memperbaiki keandalan jaringan distribusi Universitas Andalas.

\section{Kesimpulan}

Rekonfigurasi jaringan distribusi dilakukan dengan menambahkan dua saluran baru sehingga bentuk konfigurasi jaringan distribusi menjadi konfigurasi loop tetapi pada saat beroperasi jaringan tetap dalam konfigurasi radial. Rekonfigurasi jaringan distribusi listrik Universitas Andalas telah berhasil dilakukan sehingga nilai indeks keandalan ENS titik beban terbesar yaitu titik beban MIPA yang awalnya $315,191 \mathrm{kWh} /$ tahun turun menjadi 142,864 $\mathrm{kWh} /$ tahun. Lama pemadaman beban tertinggi sudah turun dari 1,176 jam pertahun menjadi 0,532 jam pertahun.

\section{Daftar Pustaka}

[1] G. T. Heydt and T. J. Graf, "Distribution System Reliability Evaluation Using Enhanced Samples in a Monte Carlo Approach," IEEE Transactions on Power Systems, vol. 25, pp. 2006-2008, 2010.

[2] A. A. Chowdhury and D. O. Koval, Eds., Power Distribution System Reliability, Practical Methods and applications (IEEE press series on power engineering. New Jersey: John Willey \& Sons, 2009.

[3] R. Billinton and R. N. Allan, Eds., Reliability Evaluation of Power System. New York: Plenum Press, 1996.

[4] I. S. Ilie, I. Hernando-Gil, and S. Z. Djokic, "Reliability equivalents of LV and MV distribution networks," in Energy Conference and Exhibition (ENERGYCON), 2012 IEEE

International, 2012, pp. 343-348.

[5] R. Billinton and R. N. Allan, Reliability Evaluation of Engineering 
System: Concepts and Techniques, second ed. New York: Plenum Press, 1992.

[6] H. Langseth and L. Portinale, "Bayesian Networks in Reliability," Reliability Engineering and Safety, vol. 92, pp. 92-108, 2007.

[7] P. M. Anderson, G. M. Chintaluri, S. M. Magbuhat, and R. F. Ghajar, "An improved reliability model for redundant protective systems-Markov models," Power Systems, IEEE

Transactions on, vol. 12, pp. 573-578, 1997.

[8] D. Vose, Quantitative Risk Analysis: A Guide to Monte Carlo Simulation Modelling. Chichester: John Willey \& Sons, 1997.

[9] M. El-Metwally, M. El-Shimy, A. Mohamed, M. Elshahed, and A. Sayed, "Reliability assessment of wind turbine operating concepts using reliability block diagrams (RBDs)," in 2017 Nineteenth International Middle East Power Systems Conference (MEPCON), 2017, pp. 430-436.

[10] R. Denning, "Applied R\&M Manual for Defence Systems," MoD, Abbey Wood, 2012.
[11] "IEEE Recommended Practice for the Design of Reliable Industrial and Commercial Power Systems (Gold Book)," IEEE Std 493-1997 [IEEE Gold Book], pp. 1-464, 1998.

\section{Biodata Penulis}

Shaumi Novila Asri, menyelesaikan pendidikan Sarjana Teknik Elektro di Universitas Andalas pada tahun 2018

Adrianti, menyelesaikan pendidikan S1 dan S2 di Universitas Sriwijaya dan Institut Teknologi Bandung. S3 diselesaikannya tahun 2015 di University of Strathclyde, Glasgow, Inggris. Saat ini bekerja sebagai dosen di Jurusan Teknik Elektro, Universitas Andalas. Bidang penelitian meliputi Proteksi Sistem Tenaga, Keandalan Sistem Tenaga, Risk Assessment dan Stabilitas Sistem Tenaga.

Muhammad Nasir, menyelesaikan pendidikan sarjana di Universitas Hasanuddin dan magister di Institut Teknologi Bandung. Bekerja sebagai dosen di Jurusan Teknik Elektro Universitas Andalas. Bidang penelitian meliputi proteksi sistem tenaga, analisa sistem tenaga dan energi management. 